\title{
General stability result for a porous thermoelastic system with infinite history and microtemperatures effect
}

\author{
Houssem Eddine Khochemane, ${ }^{1}$ \\ ${ }^{1}$ Ecole Normale Supérieure d'Enseignement Technologique de Skikda
}

July 30,2020

\begin{abstract}
In this paper, we consider a one-dimensional porous thermoelastic system with microtemperatures effects and past history term acting only on the porous equation. We show that the system is well-posed in the sens of semigroup and based on the energy method we establish a general decay result for the solutions of the system under an appropriate assumptions on the kernel. Furthermore, our result depends on the stability number that was first considered in [25]. The result of this paper improves some results in the literature.
\end{abstract}

\section{Hosted file}

Microtemperature and past history.pdf available at https://authorea.com/users/347575/ articles/473220-general-stability-result-for-a-porous-thermoelastic-system-withinfinite-history-and-microtemperatures-effect 